Article

\title{
Thermoelectric Power Generation in a Vacuum Cell of Decomposing Liquid Potassium-Ammonia Solutions
}

Jibeom Kim ${ }^{1}$, Kyuchol Shim ${ }^{1}$ and Joonhyeon Jeon ${ }^{1,2, *}$

1 Department of Energy and Advanced Material Engineering, Dongguk University-Seoul, 26, 3-ga, Pil-dong, Jung-gu, Seoul 100-715, Korea; E-Mails: jjanggu@dongguk.edu (J.K.);

kcshim@dongguk.edu (K.S.)

2 Department of Information and Communication Engineering, Dongguk University-Seoul, 26, 3-ga, Pil-dong, Jung-gu, Seoul 100-715, Korea

* Author to whom correspondence should be addressed; E-Mail: memory@dongguk.edu; Tel.: +82-2-2260-3545; Fax: +82-2-2285-3343.

Received: 15 September 2013; in revised form: 6 November 2013 / Accepted: 12 November 2013 / Published: 18 November 2013

\begin{abstract}
This paper describes the design of high-efficiency reversible thermoelectric conversion devices for thermoelectric power generation through liquid potassium-ammonia $\left(\mathrm{K}-\mathrm{NH}_{3}\right)$ solutions. The validity and effectiveness of the proposed design is verified by thermoelectric experiments using two kinds of " $U$ "-shaped vacuum cells with a $\mathrm{NH}_{3}$-gas passageway connecting both legs of " $U$ ", one of which has a waist in the middle of a liquid flow passage. The experimental results show that the gas passageway provides a stable and reliable reaction by preventing an internal pressure imbalance due to $\mathrm{NH}_{3}$ gasification during solution decomposition; hence, long-term, reversible thermoelectric power can be effectively derived by stably inducing two separate phase transitions in the cell. In addition, the effect of the narrow waist in the cell's middle is verified to cause an increase in thermoelectric conversion efficiency due to improved electric conductivity of liquid in the vacuum cell. Consequently, using these technologies in thermoelectric cell potentially leads to long-time, high-efficiency thermoelectric power generation through liquid $\mathrm{K}-\mathrm{NH}_{3}$ solutions.
\end{abstract}

Keywords: metal-ammonia; potassium-ammonia; thermoelectric materials; thermoelectric power 


\section{Introduction}

Metal-ammonia $\left(\mathrm{M}-\mathrm{NH}_{3}\right)$ solution, which is a solution of alkali metals and alkaline earth metals in liquid ammonia $\left(\mathrm{NH}_{3}\right)$, is able to produce solvated electrons at low metal concentrations as well as release free electrons by decomposing the solvated electrons at high metal concentrations. Recently, with the growth of high-tech equipment, many developments have been achieved such that the material structures of these solutions and the distribution of electrons, conductivities and distances between atoms have been measured [1-6]. Ever since Dewald and Lepoutre [7] announced the thermoelectric phenomenon in 1953, various thermoelectric experiments on these solutions have been recognized [8-17]. Nevertheless, because thermoelectric experiments on these solutions have to be carried out under restricted conditions, it is very hard to determine the accurate values for the thermoelectric power of these solutions, indispensable in the analysis of the electronic conduction mechanism [8-13]. These solutions, if not freshly prepared, become unstable (i.e., instantly jump to a new high-conducting regime before a critical degree of decomposition is reached). Because solution decomposition is catalyzed primarily by water, oxygen and most electrode metals, it proceeds aberrantly and rapidly under the given conditions; only after a few minutes does the solution easily become unstable, apparently independent of whether or not thermoelectric power is driven through the solution. This is due to the fact that it is very difficult to prepare a dilute solution of metal in liquid ammonia at the normal boiling point without contamination [18]. Most thermoelectric experiments so far have focused on measuring the thermoelectric power of these solutions; however, there has been no effort to improve the efficiency of thermoelectric power generation through the use of $\mathrm{M}-\mathrm{NH}_{3}$ solutions.

In general, it is well known that potassium-ammonia $\left(\mathrm{K}_{-} \mathrm{NH}_{3}\right)$ solution is harder to deal with than lithium-ammonia $\left(\mathrm{Li}-\mathrm{NH}_{3}\right)$ and sodium-ammonia $\left(\mathrm{Na}-\mathrm{NH}_{3}\right)$ solutions. This is because potassium $(\mathrm{K})$ is an extremely active alkali metal that oxidizes rapidly in air and is very reactive with water, generating sufficient heat to ignite the hydrogen emitted in the reaction. For this reason, the preparation and decomposition of $\mathrm{K}-\mathrm{NH}_{3}$ solutions is much more difficult than those of $\mathrm{Li}^{-} \mathrm{NH}_{3}$ or $\mathrm{Na}-\mathrm{NH}_{3}$ solutions. Hahne et al. [14], Damay et al. [15] and Niibe et al. [16] have reported the thermoelectric experimental results of these solutions in the temperature range from $-65{ }^{\circ} \mathrm{C}$ to $-50{ }^{\circ} \mathrm{C}$. Unfortunately, these thermoelectric experimental data are not in agreement with each other and thus, are not available and reliable. Such a problem is caused by the fact that during decomposition, $\mathrm{NH}_{3}$ gasification takes place rapidly on the heating side, consequently leading to a low conversion efficiency of thermoelectric power generation. Thus, a new device is needed to effectively generate the thermoelectric power of $\mathrm{K}-\mathrm{NH}_{3}$ solutions as well as to improve the thermoelectric conversion efficiency of these solutions.

The objective of this paper is to design high-efficiency reversible thermoelectric conversion devices for thermoelectric power generation through liquid potassium-ammonia $\left(\mathrm{K}_{-} \mathrm{NH}_{3}\right)$ solutions. For this purpose, we propose a novel method using a new vacuum cell for the preparation and decomposition of these solutions. The proposed cell is so arranged that a gas passageway (" $U$ ") connecting both legs of the "U" helps to provide equal inner pressure to both the end sides; further, it also has a narrow waist in the middle in order to improve the electrical conductivity. To show the effectiveness of the proposed method, two kinds of thermoelectric experiments are carried out with the liquid $\mathrm{K}_{-} \mathrm{NH}_{3}$ solutions, which are within the concentration range of 0.5-3.0 MPM (mole percent metal). The first one is to demonstrate that the gas passageway (" $U$ ") connecting both legs of the cell provides an $\mathrm{NH}_{3}$ gas-pressure 
equilibrium (inside both the cell's ends) for stably reversible thermoelectric conversion during decomposition. The second is to verify that the narrow waist in the middle of the cell improves thermoelectric conversion efficiency. All thermoelectric experiments are performed in an anhydrous and deoxidized (vacuum) state for the preparation and decomposition of pure liquid $\mathrm{K}_{-} \mathrm{NH}_{3}$ solutions; the temperature range of thermoelectric power measurements ranges from $-45{ }^{\circ} \mathrm{C}$ to $-25{ }^{\circ} \mathrm{C}$. Moreover, all generating data (temperature, current and voltage) during solution decomposition is simultaneously and exactly measured in real time. Through this new approach, the design of a high-efficiency reversible thermoelectric conversion cell provides an additional insight into the physical significance for the development of thermoelectric cells using liquid $\mathrm{M}-\mathrm{NH}_{3}$ solutions.

\section{2. $\mathrm{K}^{-\mathrm{NH}_{3}}$ Solutions}

$\mathrm{K}_{-} \mathrm{NH}_{3}$ solutions are well known to undergo much more violent and rapid decomposition on heating; however, they generate higher thermoelectric power compared to $\mathrm{Li}-\mathrm{NH}_{3}$ solutions [9-12] or $\mathrm{Na}-\mathrm{NH}_{3}$ solutions [13,14]. The dissolution process in $\mathrm{K}^{-\mathrm{NH}_{3}}$ solutions results in the potassium's valence electron being spontaneously ionized into a solvent. Because the reactivity is higher than that of $\mathrm{Li}-\mathrm{NH}_{3}$ solutions, the preparation of pure liquid $\mathrm{K}-\mathrm{NH}_{3}$ solutions requires a very difficult process of anaerobic and anhydrous environments. At low metal concentrations, this leads to the formation [16] of solvated potassium cations $\left(\mathrm{K}_{\mathrm{s}}^{+}\right)$as well as solvated electrons $\left(\mathrm{e}_{\mathrm{s}}{ }^{-}\right)$, i.e.,

$$
\mathrm{K}_{\text {metal }} \stackrel{\text { dissolution }}{\longrightarrow} \mathrm{K}_{\mathrm{s}}^{+}+\mathrm{e}_{\mathrm{s}}^{-}
$$

Note that $\mathrm{e}_{\mathrm{s}}^{-}$is a free electron solvated in liquid ammonia, which releases free electrons at high metal concentrations. The chemical formulas of $\mathrm{K}_{\mathrm{s}}{ }^{+}$and $\mathrm{e}_{\mathrm{s}}{ }^{-}$are expressed, respectively, as:

$$
\begin{aligned}
& \mathrm{K}_{\mathrm{s}}^{+}: \mathrm{K}^{+}+4 \mathrm{NH}_{3} \stackrel{\text { solvation }}{\longrightarrow} \mathrm{K}\left(\mathrm{NH}_{3}\right)_{4}^{+} \\
& \mathrm{e}_{\mathrm{s}}^{-}: \mathrm{e}^{-}+n \mathrm{NH}_{3} \stackrel{\text { solvation }}{\longrightarrow} \mathrm{e}^{-}\left(\mathrm{NH}_{3}\right)_{n}
\end{aligned}
$$

It is likely that most free $\mathrm{K}\left(\mathrm{NH}_{3}\right)_{4}{ }^{+}$will form hydrogen bonds with ammonia molecules. Also, the "isolated electron in a cavity" species, $\mathrm{e}^{-}\left(\mathrm{NH}_{3}\right)_{n}$, with $n=4-8$ are likely to be found, where a number of species contain two or more solvated electrons. The generally accepted (and probably correct) view is that a further increase in the potassium metal concentration induces a phase transition to yield a blue/bronze/copper/gold-colored liquid within which the solvated electrons are genuinely delocalized, i.e.,

$$
\mathrm{K}_{\mathrm{s}}^{+}+\mathrm{e}_{\mathrm{s}}^{-} \stackrel{\text { concentration }}{\Longrightarrow}\left[\mathrm{K}_{\mathrm{s}}^{+}+\mathrm{e}_{\mathrm{s}}^{-}\right]_{\mathrm{r}} \stackrel{\text { concentration }}{\Longrightarrow}\left[\mathrm{K}_{\mathrm{s}}\right]_{\mathrm{r}}
$$

where the symbol " $\Rightarrow$ " means an increase in the potassium metal concentration; and $r$ denotes the number of hydrogen bonds with ammonia molecules.

From the above chemical and physical properties of liquid $\mathrm{K}-\mathrm{NH}_{3}$ solutions, we can figure out the fact that at intermediately concentration, the various species containing two or more solvated electrons, have thermoelectric capacity and can also store or release free electrons by a liquid-liquid phase transition between low- and high-density concentrations. More specifically, the spin-paired species having solvated-electrons releases the free electrons by "a phase transition to metallic state" when the concentration of sodium is increased in the cooling solution. On the other hand, when adding liquid 
ammonia to the concentrated solution or when increasing the solution temperature (in a sealed vacuum vessel), the solution undergoes a phase transition to a non-metallic state (i.e., a transition from concentrated to dilute solution); then, the released free electrons are solvated again in various species (i.e., the solvated-electrons and the spin-paired species having solvated-electrons). In particular, the concentration increase in the cooling solution causes a liquid-liquid phase transition, which is likely to maximize the released electron density at the critical temperature. In general, this liquid-liquid phase separation is likely to occur when a $4 \mathrm{MPM} \mathrm{M}-\mathrm{NH}_{3}$ solution is cooled below a critical consolute temperature within the range from $-33^{\circ} \mathrm{C}$ to $-45^{\circ} \mathrm{C}$ [18]. The solution initially synthesized, if freshly prepared in a closed-vacuum cell, separates physically into a bronze metallic phase and a blue nonmetallic phase in hot and cool regions, respectively.

\section{Experimental Method}

In the previous paper [18], we have reported an exploratory thermoelectric experiment method using a "U"-shaped vacuum cell for the preparation and decomposition of liquid $\mathrm{Li}^{-\mathrm{NH}_{3}}$ solutions. It has been shown that the vacuum-cell arrangement provides advantages of not only producing a pure liquid $\mathrm{Li}-\mathrm{NH}_{3}$ solution that is in a desired concentration, but also avoids unstable decomposition (i.e., during decomposition of the solution, never jumps from the normal-conducting state to a new high-conducting regime $[1,9,10])$. Furthermore, the experimental results have demonstrated that the temperature difference on both sides of the cell engenders two separate liquid-liquid phase transitions due to the concentration changes in both the hot and cool sides-i.e., the substance in the high temperature region of the cell has a concentration below $0.1 \mathrm{MPM}$, and its color becomes nearly transparent, whereas the substance in the low temperature region has a concentration that is nearly twice the initial MPM, and the color becomes darker. Nevertheless, in order to drive the thermoelectric power of $\mathrm{K}-\mathrm{NH}_{3}$ solutions that is harder to deal with (i.e., has higher activity on heating) than $\mathrm{Li}^{-\mathrm{NH}_{3}}$ solutions, special care needs to be taken to provide equal ammonia-gas pressure to the inside (both sides) of the cell (i.e., the violent decomposition in the hot side of the sealed cell rapidly produces a lot of $\mathrm{NH}_{3}$ gasification, thereby causing an unbalance of pressures inside both the legs of the "U").

In order to carry out thermoelectric experiments demonstrating the effect of the $\mathrm{NH}_{3}$ gas-pressure equilibrium in a vacuum cell of decomposing $\mathrm{K}^{-\mathrm{NH}_{3}}$ solution along with the improvement of the current efficiency according to a liquid flow increase in the middle, we use two kinds of cells, both of which is a " $U$ " shaped Pyrex vacuum cell type with and without the narrow waist in the middle. Figure 1 shows the narrow-waisted and the no-waisted cells used in this work, where the passage control valve " $\mathrm{C}$ " is used to monitor and control gas flow passing through the passageway. The inside of these cells is kept at a vacuum state for the preparation and decomposition of pure liquid $\mathrm{K}-\mathrm{NH}_{3}$ solutions, and the thermoelectric power data (current, voltage and temperature) are simultaneously measured at the electrodes $\left(\mathrm{B}_{1}, \mathrm{~B}_{2}\right)$ and thermocouples $\left(\mathrm{A}_{1}, \mathrm{~A}_{2}\right)$ on both closed ends. Pure liquid $\mathrm{K}-\mathrm{NH}_{3}$ solutions which are in the concentration range of 0.5-3.0 MPM are initially prepared in the cell: during decomposition of these solutions, the concentration range in the cool-side region is increased up to 1.0-6.0 MPM (normal conducting state) [18]. Figure 2 shows an overall thermoelectric experiment system used for this purpose, and the related specifications are also indicated in Table 1. 
Figure 1. " $U$ " shaped Pyrex cells: (a) no-waisted cell and (b) waisted cell.

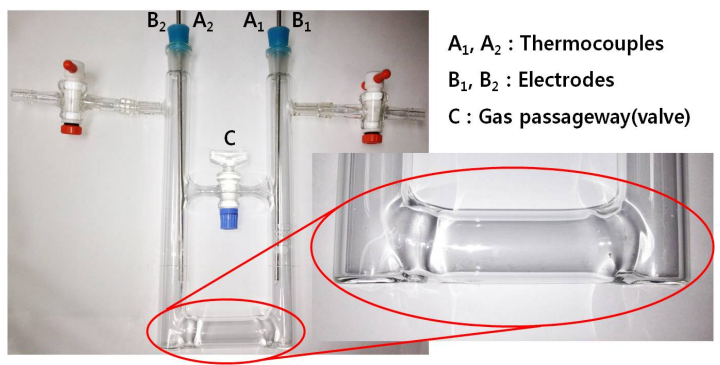

(a)

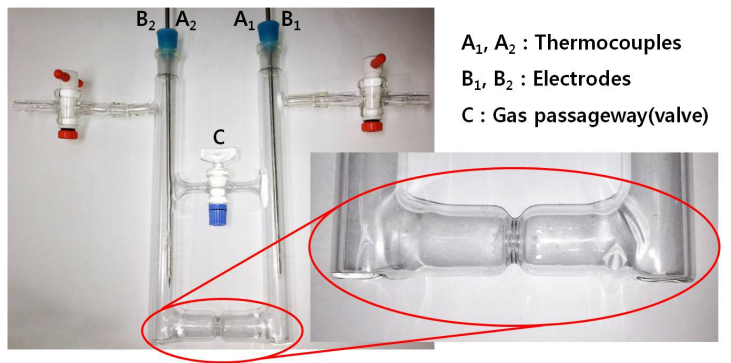

(b)

Figure 2. Overall thermoelectric experiment system used in this study for the preparation and decomposition of pure potassium-ammonia $\left(\mathrm{K}^{\left.-\mathrm{NH}_{3}\right)}\right.$ solutions: injection of pure potassium into the cell is carried out in the glove box with an anhydrous and deoxidized inside. After that, both preparation and decomposition of the solutions proceed in the cell's inside, in which a vacuum is recreated after the cell is connected to this system. $\mathrm{A}: \mathrm{NH}_{3}$ gas input valve; $\mathrm{B}_{1}$ : Liquid $\mathrm{NH}_{3}$ input valves; $\mathrm{B}_{2}$ : $\mathrm{NH}_{3}$ gas exhausting valves; $\mathrm{C}$ : Vacuum control valve; and D: silicon oil exhausting trap.

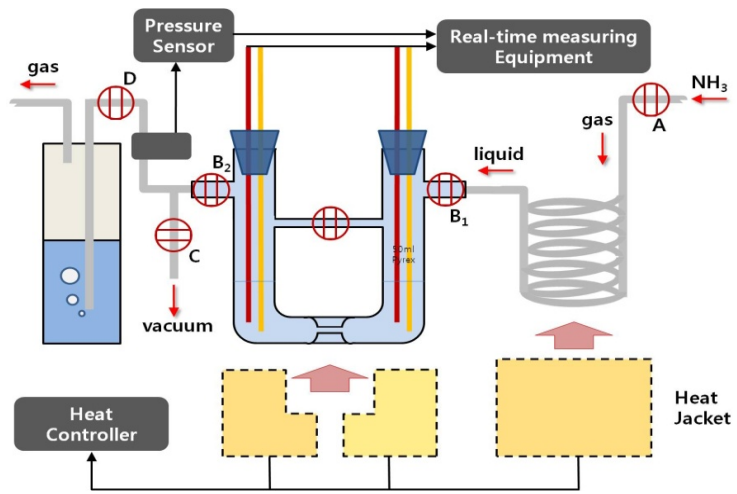

Table 1. The related specifications of Figures 1 and 2.

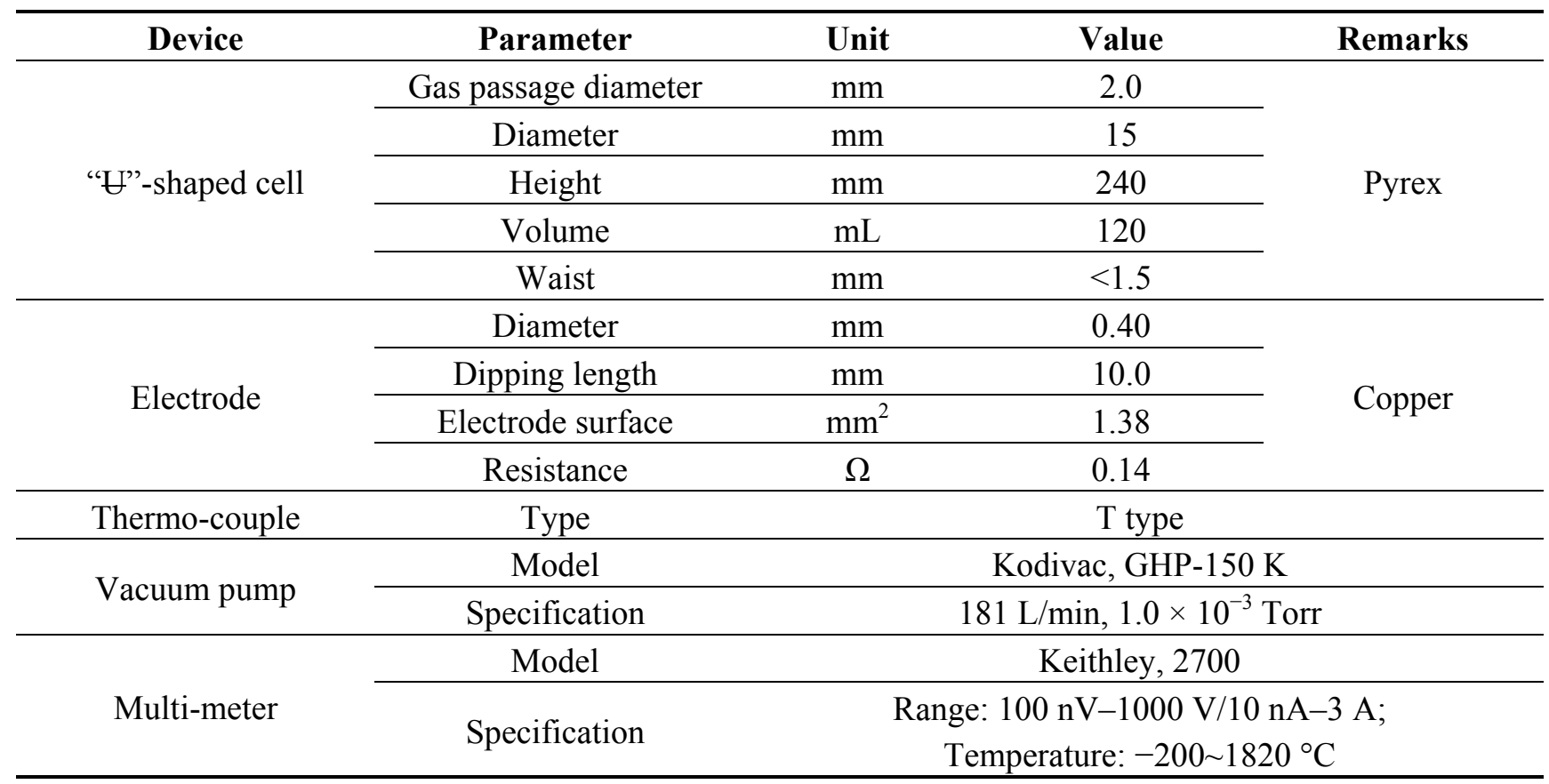


The process for the preparation of pure liquid $\mathrm{K}-\mathrm{NH}_{3}$ solutions, based on this system, is similar to the case of $\mathrm{Li}-\mathrm{NH}_{3}$ solutions [18]. The cell is housed in a thermostatic container, which is set to keep the temperature at $-45^{\circ} \mathrm{C}$. In addition, a vacuum is created inside the cell until the pressure in the $10^{-3}$ Torr range is reached. This is to deoxidize the inside of the cell and to make a pure solution in an anhydrous state. Subsequently, a desired amount of pure potassium (99.999\%) is injected into the vacuum cell, and liquid $\mathrm{NH}_{3}$ is also injected into the cell until $50 \mathrm{~mL}$ of liquid $\mathrm{NH}_{3}$ is filled. During the solution preparation, the pressure in the vacuum cell is about 760 Torr. To induce two separate phase transitions in the inside of the cell, a temperature difference between both sides is created. To do so, as shown in Figure 2, two heat generators are integrated on both sides of the cell and are housed (together with the cell) in a thermostatic container, which is set to keep the ambient temperature at $-45^{\circ} \mathrm{C}$. Two heat sources increase or decrease in the temperature range from $-45{ }^{\circ} \mathrm{C}$ to $-25{ }^{\circ} \mathrm{C}$, and are controlled within the accuracy of $\pm 0.02{ }^{\circ} \mathrm{C}$. To induce reversible reactions in the cell (for long-time thermoelectric power generation), the two heat sources are switched on both sides of the cell (Figure 3)-i.e., the hot-side heat source on either side is controlled so that the temperature is increased from $-45{ }^{\circ} \mathrm{C}$ to $-25^{\circ} \mathrm{C}$, whereas the cool-side heat source on the opposite side is controlled so that the temperature is decreased from $-25{ }^{\circ} \mathrm{C}$ to $-45^{\circ} \mathrm{C}$. This switching of the two heat sources is automatically carried out when the temperature difference between type- $\mathrm{T}$ thermocouples on both the end sides is approximately $\pm 20^{\circ} \mathrm{C}$ (the minus sign is due to the switching between the two heat sources). As aforementioned, this switching of the two heat sources on both sides of the cell will induce the decomposition of concentrated solutions, which are at a concentration range of 1.0-6.0 MPM, nearly two times the initial MPM.

Figure 3. Control of the two heat sources on both sides of the cell: high and low temperatures induce "a phase transition to the dilute density" and "a phase transition to the concentrated density" in both sides of the cell, respectively.

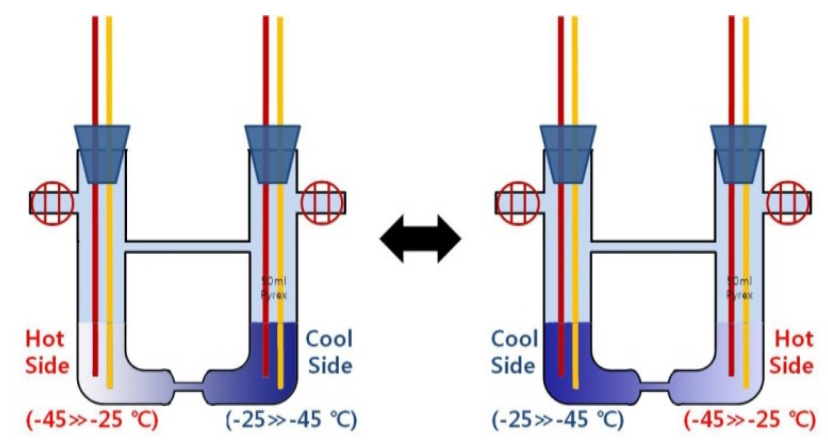

\section{Results and Discussion}

Two kinds of thermoelectric experiments are performed with six kinds of pure liquid $\mathrm{K}_{-} \mathrm{NH}_{3}$ solutions, which are at the concentrations of 0.5, 1.0, 1.5, 2.0, 2.5 and 3.0 MPM. The first thermoelectric experiment is to show the effectiveness of the gas passageway (" $U$ ") for the $\mathrm{NH}_{3}$ gas-pressure equilibrium in a cell of decomposing $\mathrm{K}_{-} \mathrm{NH}_{3}$ solution, and the no-waisted cell (Figure 1a) is used for this purpose. Next, to verify the effect of the narrow waist for the improvement of the current efficiency, according to a liquid flow increase in the middle, the waisted cell (Figure 1b) is compared to the no-waisted cell of the same size. Then, each solution of the desired concentration is made by 
synthesizing a small piece of pure potassium (such as 0.3933, 0.7906, 1.1919, 1.5974, 2.0070 and $2.4210 \mathrm{~g}$ ) upon the injection of liquid $\mathrm{NH}_{3} 50 \mathrm{~mL}(34.16 \mathrm{~g})$ into the cell. A single decomposition run under a given concentration is carried out for about $1.2 \mathrm{~h}$.

Figures 4 and 5 show the experimental results of measuring, in real time, the generating current and voltage due to the temperature difference $(\Delta T)$ on both sides of the no-waisted cell during solution decomposition, where $\Delta T$ is controlled in the range of $-20{ }^{\circ} \mathrm{C} \leq \Delta T \leq 20^{\circ} \mathrm{C}$ for a given $1.2 \mathrm{~h}$. The related data of Figures 4 and 5 are also indicated in Table 2, where the resistance and the pressure are, respectively, the electrical resistance of liquid and the vapor pressure of gas that are in the cell of the decomposing $\mathrm{K}-\mathrm{NH}_{3}$ solution. From Figure 4, it can be observed that the cell provided with the gas passageway can effectively derive an improved thermoelectric power cycles, as compared to Figure 4 in reference [18], by using a vacuum cell without the gas passageway.

Figure 4. Thermoelectric characteristics due to $\Delta T$ variation for (a) 0.5 ; (b) 1.0 ; (c) 1.5 ; (d) 2.0; (e) 2.5; and (f) 3.0 MPM (mole percent metal).

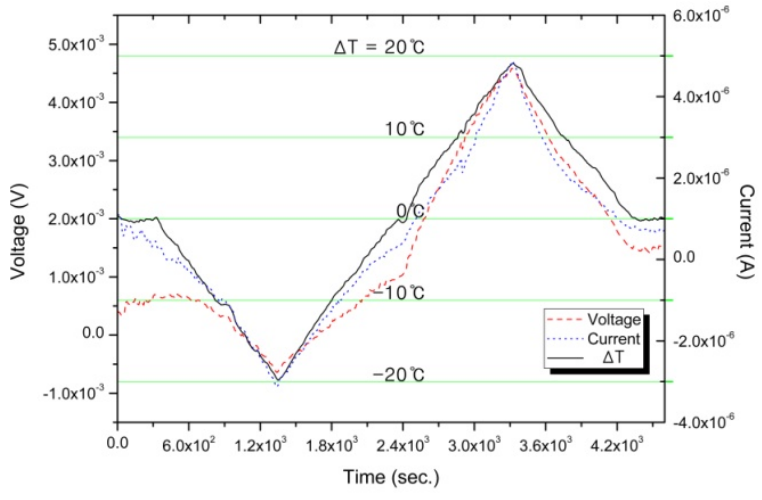

(a)

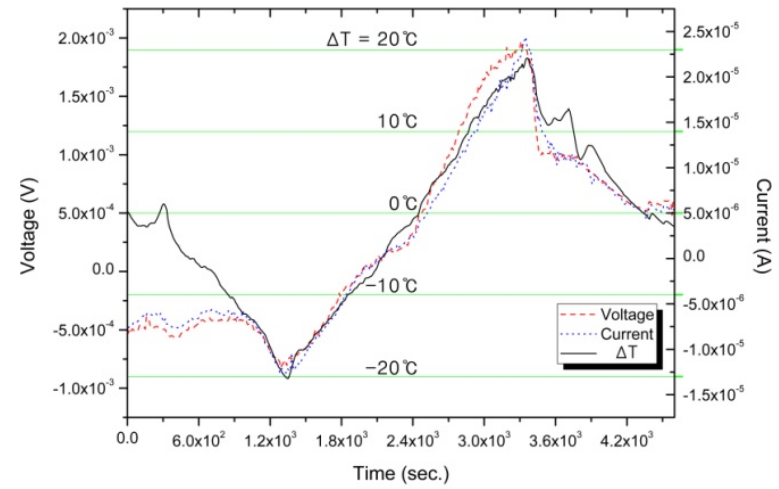

(c)

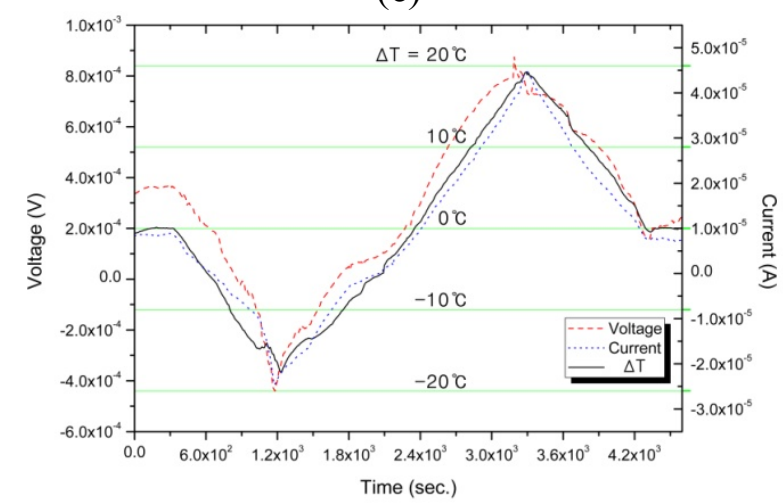

(e)

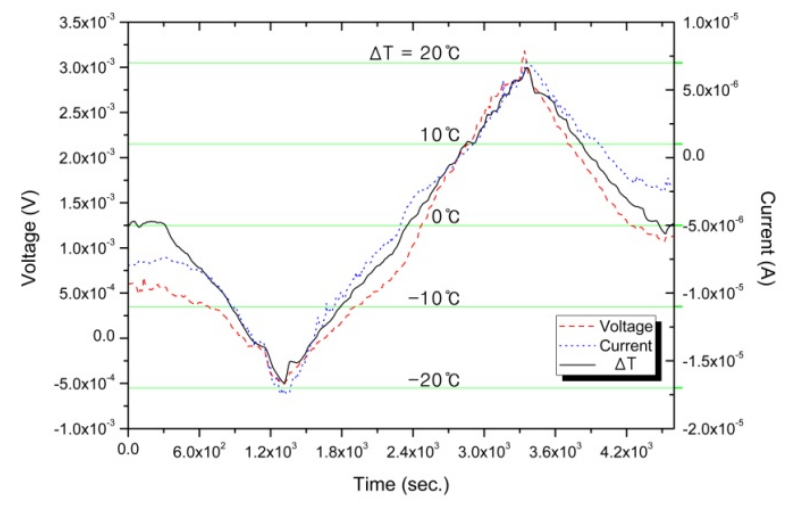

(b)

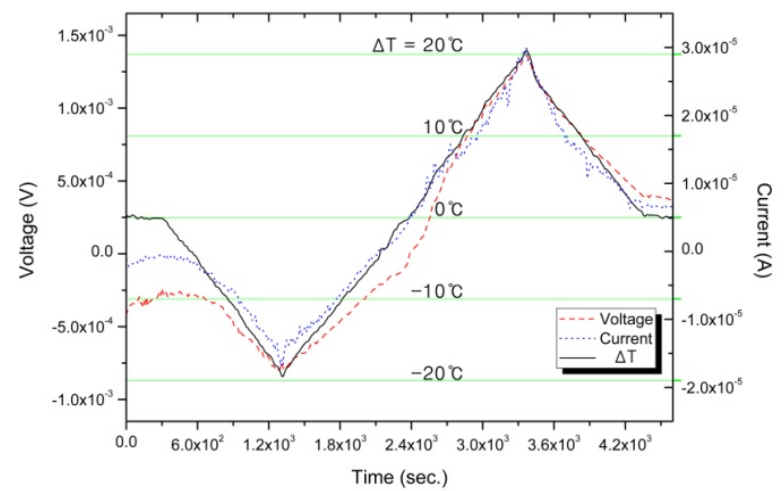

(d)

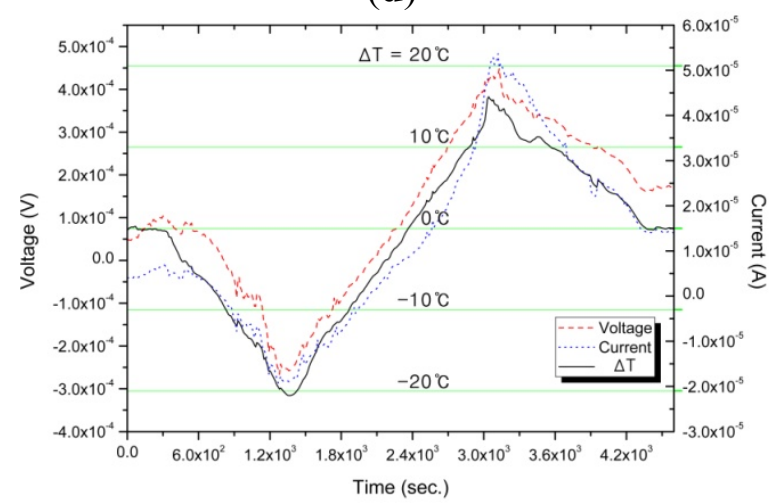

(f) 
In particular, the proposed device provides excellent stable linearity for reversible reaction-i.e., both voltage and current increase or decrease simultaneously as $\Delta T$ increases or decreases with the change of time from $0 \mathrm{~h}$ to $1.2 \mathrm{~h}$. This linearity between the voltage and current is also shown in Figure 5, where the slope of a line represents the reciprocal of an electrical resistance which is constant within an error tolerance range (see Table 2).

Figure 5. The current $v s$. voltage characteristics (for $1.2 \mathrm{~h}$ ) due to (a) 0.5 ; (b) 1.0 ; (c) 1.5; (d) 2.0; (e) 2.5; and (f) 3.0 MPM.

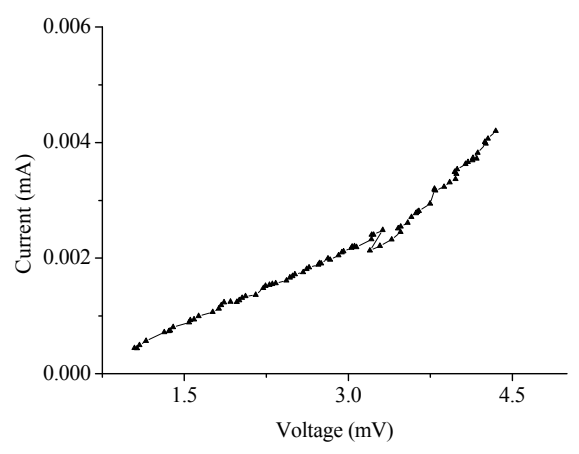

(a)

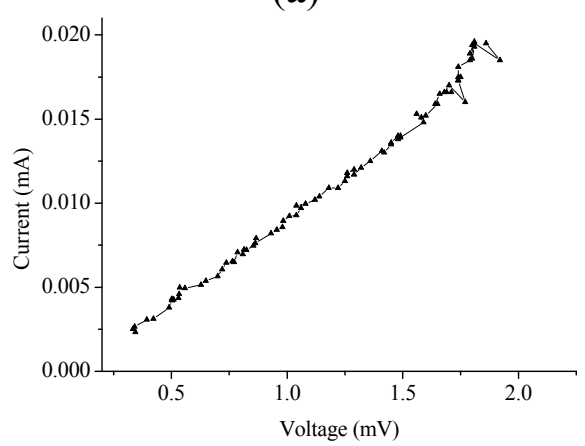

(c)

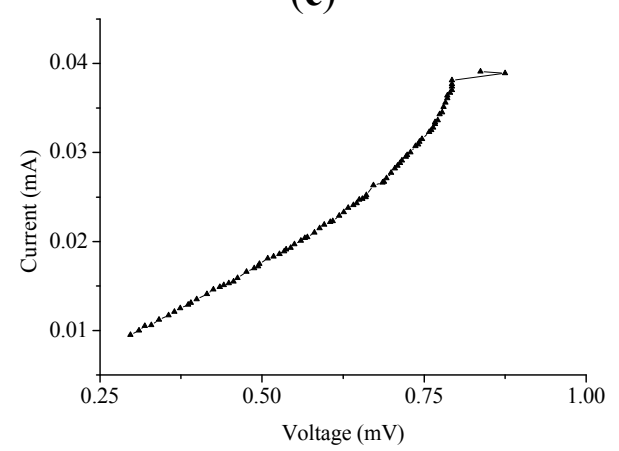

(e)

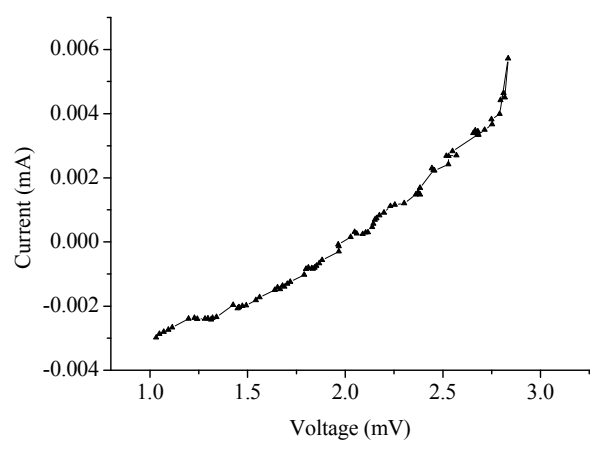

(b)

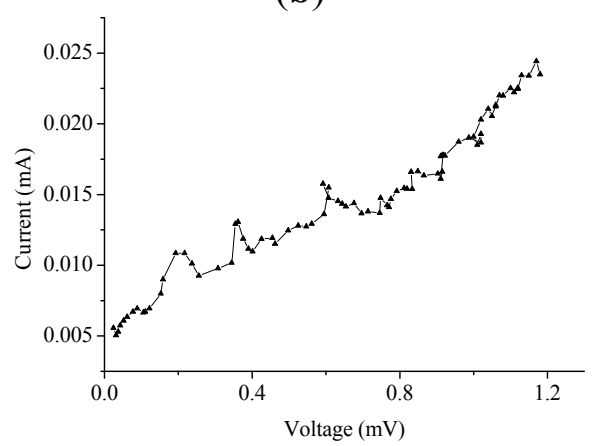

(d)

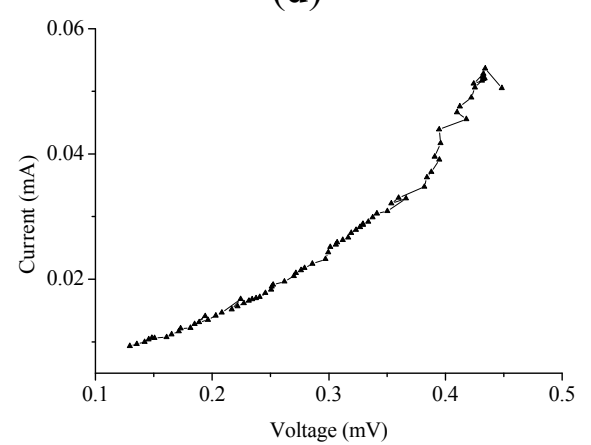

(f)

This electrical resistance is an important factor in determining the electrical conductivity of decomposing $\mathrm{K}_{-} \mathrm{NH}_{3}$ solution in a cell. In addition, as indicated in Table 2, an increase in the potassium concentration shows that the peak-to-peak voltage decreases with an average of $31 \%$ per 0.5 MPM; however, the peak-to-peak current increases with a higher average of 57\% per $0.5 \mathrm{MPM}$. This result is due to the improved electrical conductivity of liquids, i.e., the average $655.458 \Omega$ in $0.5 \mathrm{MPM}$ is reduced considerably to $9.798 \Omega$ in $3.0 \mathrm{MPM}$. Remarkably, during decomposition, the vapor pressure (due to $\mathrm{NH}_{3}$ gasification) inside the cell is shown to be within the acceptable limits (a maximum variation of $9 \%$ ) and appears to be perfectly controlled by the gate passageway, which helps to provide 
equal inner pressure to both the end sides. From these results, we can figure out that the gas passageway provides an improved reversibility for reliable and stable thermoelectric power conversion through $\mathrm{K}_{-} \mathrm{NH}_{3}$ solutions. Consequently, it can play a critical role in realizing thermoelectric devices for deriving long-time, high-efficiency thermoelectric power.

Table 2. Related data of Figures 4 and 5.

\begin{tabular}{ccccccccc}
\hline MPM & $\mathbf{K}(\mathbf{g})$ & $\begin{array}{c}\mathbf{N H}_{3} \\
(\mathbf{m L})\end{array}$ & $\begin{array}{c}\text { Peak-to-peak } \\
\text { voltage }(\mathbf{m V})\end{array}$ & $\begin{array}{c}\text { Peak-to-peak } \\
\text { current }(\mathbf{m A})\end{array}$ & $\begin{array}{c}\text { Voltage } \\
\text { range }(\mathbf{m V})\end{array}$ & $\begin{array}{c}\text { Current range } \\
(\mathbf{m A})\end{array}$ & $\begin{array}{c}\text { Resistance } \\
(\mathbf{\Omega})\end{array}$ & $\begin{array}{c}\text { Pressure } \\
(\mathbf{B a r})\end{array}$ \\
\hline 0.5 & 0.3933 & 50 & 5.224 & 0.00797 & $-0.644 \sim 4.580$ & $-0.0031 \sim 0.0048$ & $655.458 \pm 61.284$ & $1.33 \pm 0.17$ \\
1.0 & 0.7906 & 50 & 3.700 & 0.02458 & $-0.520 \sim 3.180$ & $-0.0175 \sim 0.0070$ & $150.528 \pm 24.256$ & $1.55 \pm 0.16$ \\
1.5 & 1.1919 & 50 & 2.797 & 0.03730 & $-0.827 \sim 1.970$ & $-0.0129 \sim 0.0244$ & $74.987 \pm 4.577$ & $1.73 \pm 0.17$ \\
2.0 & 1.5974 & 50 & 2.161 & 0.04690 & $-0.801 \sim 1.360$ & $-0.0169 \sim 0.0300$ & $46.077 \pm 14.008$ & $1.82 \pm 0.17$ \\
2.5 & 2.0070 & 50 & 1.316 & 0.06920 & $-0.441 \sim 0.875$ & $-0.0245 \sim 0.0447$ & $19.017 \pm 1.964$ & $1.87 \pm 0.15$ \\
3.0 & 2.4210 & 50 & 0.714 & 0.07287 & $-0.266 \sim 0.448$ & $-0.0192 \sim 0.0537$ & $9.798 \pm 1.387$ & $1.89 \pm 0.13$ \\
\hline
\end{tabular}

It is known that the electric resistivity of a liquid may be deduced by measuring the value of the electrically conductive resistance between two electrodes immersed in the liquid. The resistivity $r$ (that is the inverse of the conductivity) will be, in that case, theoretically provided with the formula: $r=$ resistance/(liquid volume) in $\Omega \mathrm{cm}^{-3}$, i.e., it will be equal to the measured resistance divided by the volume between the electrodes. Based on this theoretical work, Figure 6 illustrates the electrical conductivity results of the liquids, according to the concentration for the performance comparison of the waisted and the no-waisted cells (see Figure 2).

Figure 6. Performance comparison of the waisted and no-waisted cells due to potassium concentration (the current and voltage data for each given MPM is to average the measured data with about 1.2 h): (a) current; (b) voltage; (c) resistivity; and (d) conductivity.

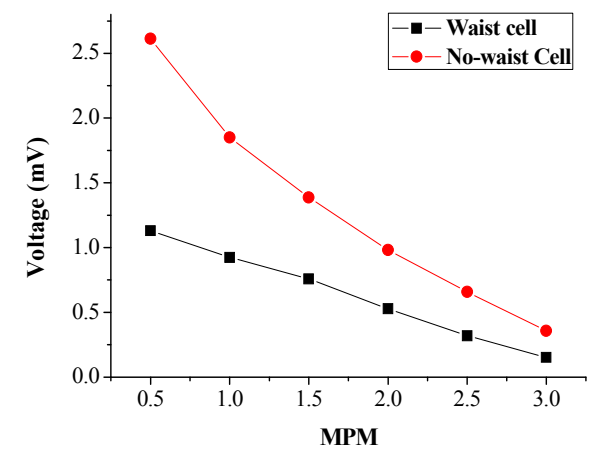

(a)

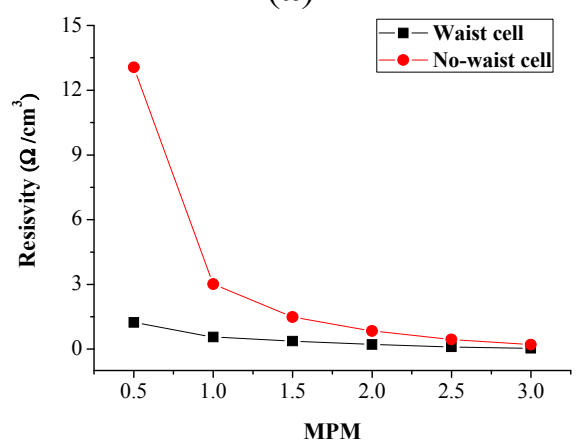

(c)

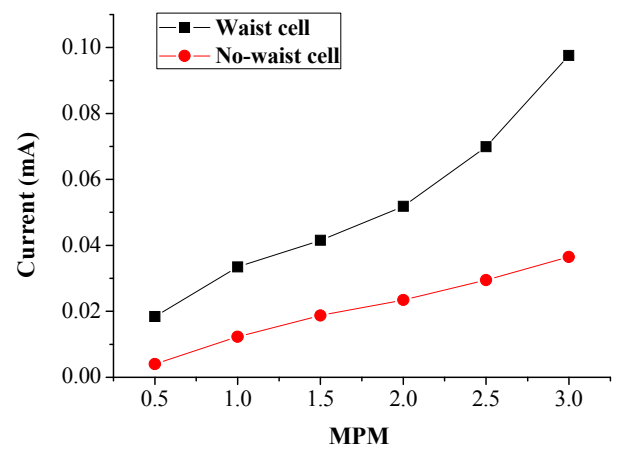

(b)

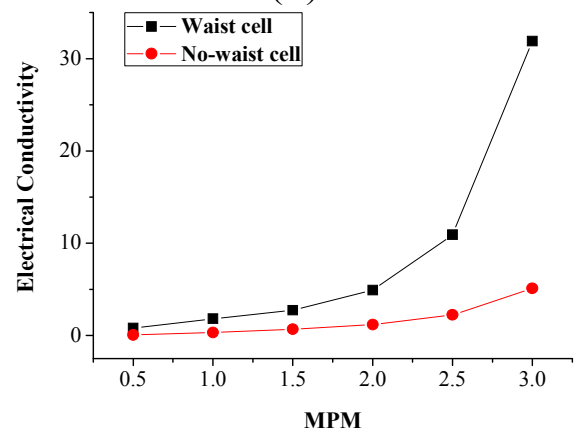

(d) 
The related data is also indicated in Table 3, where all current and voltage data are time average values calculated from the measured data for about $1.2 \mathrm{~h}$. From these results, it can be found that the waisted cell generates an average of 0.5 times lower voltage, but an average of 1.8 times higher current than the no-waisted cell-i.e., the waisted cell amplifies current, not voltage. This is due to the fact that the resistance reduction (Figure 6c) engenders electrical conductivity improvement (Figure 6d) of decomposing liquid solutions. In addition, in the low concentration range below 1.5 MPM (corresponding to about 3.0 MPM in the cool side region during decomposition), the waisted cell's current amplification is slightly high, but the voltage drop is relatively much higher, whereas in the high concentration range beyond 2.0 MPM (corresponding to about 4.0 MPM in the cool side region), the current amplification is much higher, but the voltage drop is relatively slightly higher.

Table 3. Related data of Figure 6.

\begin{tabular}{ccccccc}
\hline MPM & $\begin{array}{c}\text { Potassium } \\
(\mathbf{g})\end{array}$ & $\begin{array}{c}\text { Average } \\
\text { Voltage }(\mathbf{m V})\end{array}$ & $\begin{array}{c}\text { Average } \\
\text { Current }(\mathbf{m A})\end{array}$ & $\begin{array}{c}\text { Resistance } \\
(\boldsymbol{\Omega})\end{array}$ & $\begin{array}{c}\text { Resistivity } \\
\left(\mathbf{\Omega} \mathbf{~ c m}^{-\mathbf{3}} \mathbf{)}\right.\end{array}$ & $\begin{array}{c}\text { Conductivity } \\
\left(\mathbf{\Omega}^{-\mathbf{1}} \mathbf{c m}^{\mathbf{3}} \mathbf{)}\right.\end{array}$ \\
\hline 0.5 & 0.3933 & $1.1310(2.6130)$ & $0.0184(0.0040)$ & $61.4674(653.2500)$ & $1.2293(13.0650)$ & $0.8134(0.0765)$ \\
1.0 & 0.7906 & $0.9240(1.8490)$ & $0.0335(0.0123)$ & $27.5821(150.3252)$ & $0.5516(3.0065)$ & $1.8128(0.3326)$ \\
1.5 & 1.1919 & $0.7580(1.3880)$ & $0.0415(0.0187)$ & $18.2651(74.2246)$ & $0.3653(1.4845)$ & $2.7375(0.6736)$ \\
2.0 & 1.5974 & $0.5270(0.9810)$ & $0.0518(0.0234)$ & $10.1737(41.9231)$ & $0.2035(0.8385)$ & $4.9146(1.1927)$ \\
2.5 & 2.0070 & $0.3200(0.6580)$ & $0.0699(0.0346)$ & $4.5780(22.3051)$ & $0.0916(0.4461)$ & $10.9219(2.2416)$ \\
3.0 & 2.4210 & $0.1530(0.3570)$ & $0.0976(0.0365)$ & $1.5676(9.7808)$ & $0.0314(0.1956)$ & $31.8954(5.1120)$ \\
\hline
\end{tabular}

$(x)$ denotes the current and voltage data measured in the no-waisted cell.

Figure 7, which uses the waisted and the no-waisted cells, shows the current vs. voltage (i.e., the inverse of an electrical resistance) characteristics and 2.0 MPM thermoelectric conversion efficiency over the $\Delta T$ interval of $0-20{ }^{\circ} \mathrm{C}$ (corresponding to the time interval from $2400 \mathrm{~s}$ to $3200 \mathrm{~s}$ in the case of Figure 4), where all data is determined by simultaneously measuring the generating current and voltage in cells of decomposing $\mathrm{K}_{-} \mathrm{NH}_{3}$ solutions, as mentioned above.

From Figure 7a, the electrical conductivity of liquid in the waisted cell is verified to be vastly improved, much more markedly than in the no-waisted cell. In particular, the average thermoelectric power increase per degree, calculated with the electrode surface, is approximately $10.0 \mathrm{~mW} \mathrm{~m} /{ }^{-2} \mathrm{C}$ in the case of the waste cell, whereas it is $5.5 \mathrm{~mW} \mathrm{~m}^{-2} /{ }^{\circ} \mathrm{C}$ in the case of the no-waste cell (Figure $7 \mathrm{~b}$ ). This corresponds to a performance increase by approximately $81 \%$. Consequently, the waisted cell leads to much higher electrical conductivity of liquid than the no-waisted cell, and thereby, can drive higher-efficiency thermoelectric power. From these results, we can figure out that during solution decomposition, the narrow waist in the cell's middle leads to increasing the flow of free electrons from the high- to low-temperature regions. Consequently, this produces an avalanche amplification of electrical current in the middle, resulting in a situation comparable to the Venturi effect in hydrodynamics $[19,20]$. 
Figure 7. Thermoelectric comparison of the waisted and no-waisted cells over the $\Delta T$ interval of $0-20{ }^{\circ} \mathrm{C}$ (the time interval from $2400 \mathrm{~s}$ to $3200 \mathrm{~s}$ ): (a) real-time current $v s$. voltage characteristics; and (b) 2.0 MPM thermoelectric power density.
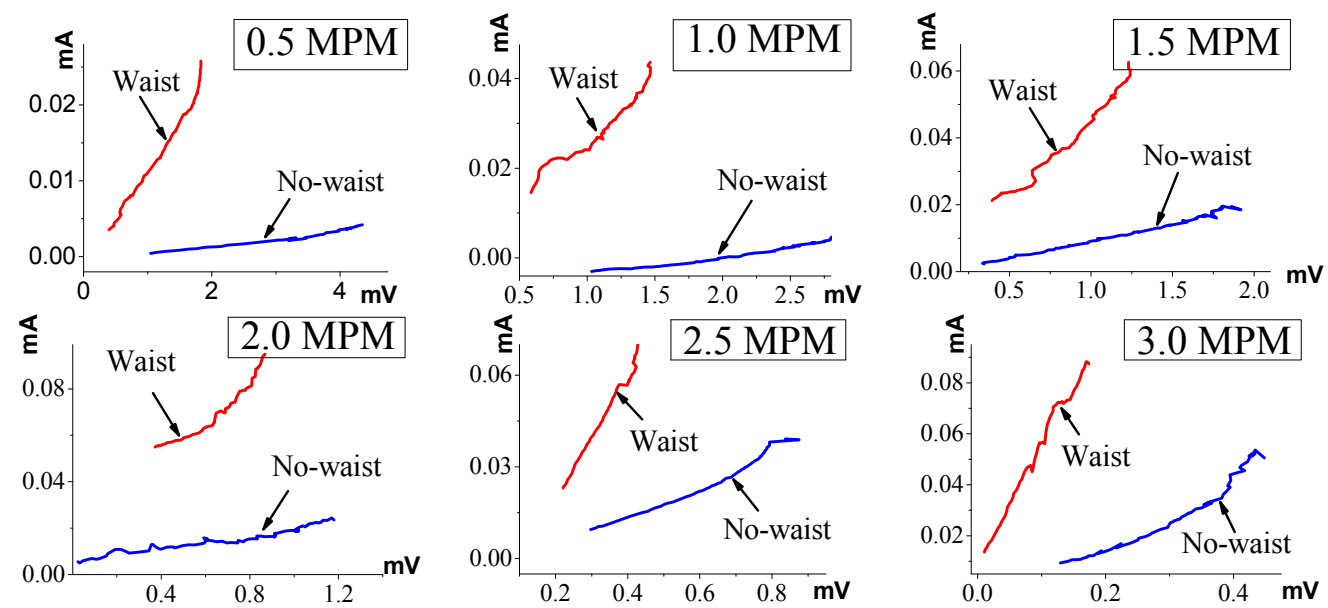

(a)

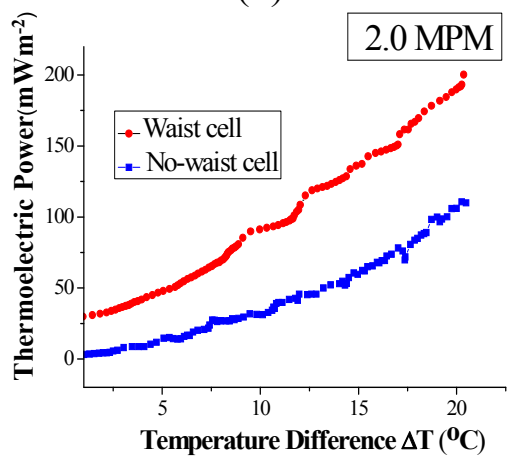

(b)

\section{Conclusions}

For high-efficiency thermoelectric power generation through liquid $\mathrm{K}-\mathrm{NH}_{3}$ solutions, the design of thermoelectric devices in this study has been considered capable of providing both a $\mathrm{NH}_{3}$-gas-pressure equilibrium and a thermoelectric conversion efficiency improvement in the cell of decomposing $\mathrm{K}-\mathrm{NH}_{3}$ solutions. For this purpose, we have developed a thermoelectric cell provided with a gas passageway (" $U$ ") connecting both legs of the "U" and a narrow waist in the middle, respectively, for the $\mathrm{NH}_{3}$-vapor pressure equilibrium and thermal transfer reduction between hot and cold regions of the cell. Thermoelectric experimental results have proven that the gas passageway provides an improved reversibility that effectively generates improved (reverse-direction) thermoelectric power. Further, the results indicate that the narrow waist also leads to the improvement of the electrical conductivity of the solution by reducing the thermal transfer between hot and cold regions of a cell. Consequently, by using this technology, the proposed thermoelectric cell has been proven to potentially lead to long-term (reversible), high-efficiency thermoelectric power generation through liquid $\mathrm{K}-\mathrm{NH}_{3}$ solutions. Hence, in order to design high-efficiency reversible thermoelectric conversion devices using liquid $\mathrm{K}-\mathrm{NH}_{3}$ solutions, a solution to the problem encountered in the previous technologies is found. 


\section{Acknowledgments}

This work was supported by the Dongguk University Research Fund of 2013.

\section{Conflicts of Interest}

The authors declare no conflict of interest.

\section{References}

1. Hayama, S.; Skipper, N.T.; Wasse, J.C.; Thompson, H. X-ray diffraction studies of solutions of lithium in ammonia: The structure of the metal-nonmetal transition. J. Chem. Phys. 2002, 116, 2991-2996.

2. Wasse, J.C.; Shusaku, H.; Masmanidis, S.; Stebbings, S.L.; Skipper, N.T. The structure of lithium-ammonia and sodium-ammonia solutions by neutron diffraction. J. Chem. Phys. 2003, 118, 7486-7494.

3. Salter, T.E.; Mikhailov, V.A.; Evans, C.J.; Ellis, A.M. Infrared spectroscopy of $\mathrm{Li}\left(\mathrm{NH}_{3}\right)_{n}$ clusters for $n=4-7$. J. Chem. Phys. 2006, 125, 034302:1-034302:10.

4. Salter, T.E.; Ellis, A.M. Coordination structures of lithium-methylamine clusters from infrared spectroscopy and ab initio calculations. J. Chem. Phys. 2007, 127, 144314:1-144314:8.

5. Jovanovic, V.; Ghamaty, S.; Krommenhoek, D.; Bass, J.C. High Coefficient of Performance Quantum Well Thermoelectric Nano Cooler. In Proceedings of the ASME 2007 InterPACK Conference Collocated with the ASME/JSME 2007 Thermal Engineering Heat Transfer Summer Conference, Vancouver, BC, Canada, 8-12 July 2007; pp. 595-601.

6. Edwards, P.P. Polarons, bipolarons, and possible high- $\mathrm{T}_{c}$ superconductivity in metal-ammonia solutions. J. Supercond. 2000, 13, 933-946.

7. Dewald, J.F.; Lepoutre, G. The thermoelectric properties of metal-ammonia solutions. I. The thermoelectric power of sodium and potassium solutions at $-33^{\circ}$. J. Am. Chem. Soc. 1953, 76, 3369-3373.

8. Joshua, J.; Morrel, H.C. Metal-nonmetal transition in metal-ammonia solutions. Phys. Rev. B 1976, 13, 1548-1568.

9. Arendt, P. Dissipationless electric current flow through decomposing liquid metal-ammonia solutions between copper electrodes. Electrochim. Acta. 1985, 30, 709-718.

10. Arendt, P. Circulating currents in tubes of decomposing liquid lithium-ammonia solutions in the high-conducting state. Electrochim. Acta. 1986, 31, 445-449.

11. Arendt, P. The xerogel made from decomposing liquid metal-ammonia solutions-A solid material which carries current densities of $10^{5} \mathrm{~A} \mathrm{~cm}^{-2}$ at room temperature. J. Phys. Chem. Solids 1988, 49, 511-517.

12. Arendt, P. Change in electrical conductivity of a gel made from decomposing liquid metal-ammonia solutions as the gel is dried to a xerogel. Solid State Commun. 1990, 74, 559-565.

13. Ogg, R.A. Bose-Einstein condensation of trapped electron pairs. Phase separation and super-conductivity of metal-ammonia. Phys. Rev. 1946, 69, 243-244. 
14. Hahne, S.; Krebs, P.; Schindewolf, U. Electrical conductivity and thermopower of metal ammonia solutions. Ber. Bunsenges. Phys. Chem. 1976, 80, 804-808.

15. Damay, P.; Chieux, P.; Lepoutre, G. Equilibrium model for the interpretation of the conduction properties of metal-ammonia solutions. Can. J. Chem. 1977, 55, 2211-2216.

16. Niibe, M.; Nakamura, Y.; Shimoji, M. Electrical conductivity and thermoelectric power of potassium-ammonia solutions. J. Phys. Chem. 1982, 86, 4513-4515.

17. Wasse, J.C.; Hayama, S.; Skipper, N.T.; Benmore, C.J.; Soper, A.K. The structure of saturated lithium- and potassium-ammonia solutions as studied by using neutron diffraction. J. Chem. Phys. 2000, 112, 7147-7151.

18. Jeon, J.; Kim, J. Thermoelectric experiment of a fluid lithium-ammonia solution in a U-shaped Pyrex tube with highly pure vacuum state. Adv. Sci. Lett. 2012, 8, 550-554.

19. Taubert, D.; Schinner, G.J.; Tranitz, H.P.; Wegscheider, W.; Tomaras, C.; Kehrein, S.; Ludwig, S. Electron-avalanche amplifier based on the electronic Venturi effect. Phys. Rev. B 2010, 82, 161416:1-161416:4.

20. Lee, S.; Lee, H. Thermodynamics of small electron-bound water clusters. Bull. Korean Chem. Soc. 2003, 24, 802-804.

(C) 2013 by the authors; licensee MDPI, Basel, Switzerland. This article is an open access article distributed under the terms and conditions of the Creative Commons Attribution license (http://creativecommons.org/licenses/by/3.0/). 